\title{
Erratum to: Impact of the energy-based and location-based LEACH secondary cluster aggregation on WSN lifetime
}

\author{
Oluwatosin Ahmed Amodu' ${ }^{1}$ Raja Azlina Raja Mahmood ${ }^{1}$
}

Published online: 8 August 2017

(C) Springer Science+Business Media, LLC 2017

\section{Erratum to: Wireless Netw \\ DOI 10.1007/s11276-016-1414-9}

$$
E_{T X}= \begin{cases}l \times E_{\text {elec }}+l \times \varepsilon_{f s} \times d^{2} & \text { when } d \leq d_{0} \\ l \times E_{\text {elec }}+l \times \varepsilon_{m p} \times d^{4} & \text { when } d>d_{0}\end{cases}
$$

In the original publication, Equation 4.1 and the value of initial energy in Table 11 were wrongly published. The above-mentioned errors are corrected with this erratum.

1. In Equation 4.1, the correct expression as used in the simulations is given below:
2. For Table 11, the initial energy is $0.5 \mathrm{~J}$ as shown in Section 4.3, line 2 .
The online version of the original article can be found under doi:10.1007/s11276-016-1414-9.

Oluwatosin Ahmed Amodu

amoduahmedtosin@gmail.com

Raja Azlina Raja Mahmood

raja_azlina@upm.edu.my

1 Department of Communication Technology and Network,

Faculty of Computer Science and Information Technology,

Universiti Putra Malaysia, 43400 UPM, Serdang,

Selangor Darul Ehsan, Malaysia 